\title{
PENDAMPINGAN PENYAJIAN DAN PENGOLAHAN DATA DEMOGRAFI KESEHATAN PENDUDUK APARAT DESA NEGERI HUTUMURI KECAMATAN LEITIMUR SELATAN KOTA AMBON
}

https://doi.org/10.33024/jkpm.v4i6.4344

\author{
Johan Bruiyf Bension ${ }^{1}$, Ferry Kondo Lembang ${ }^{2 *}$, Carlos Salemba \\ Latuihamallo ${ }^{3}$, Samin Radjid ${ }^{4}$, Asrul Irfanullah ${ }^{5}$ \\ 1,2,3,4,5 Universitas Pattimura Ambon
}

Email Korespondensi: ferrykondolembang@gmail.com

\begin{abstract}
ABSTRAK
Negeri Hutumuri merupakan desa terpadat di wilayah Kecamatan Leitimur Selatan Kota Ambon dengan jumlah penduduk mencapai 4.657 jiwa serta kepadatan penduduk sebesar 310 jiwa setiap $\mathrm{km}^{2}$. Keberadaan profil status jumlah penduduk yang lebih besar memungkinkan peluang munculnya berbagai persoalan kependudukan khususnya kesehatan penduduk apabila tidak dikelola dengan baik. Tujuan dari program Pengabdian Kepada Masyarakat ini adalah untuk meningkatkan pengetahuan aparat desa sebagai ujung tombak pembangunan desa terkait penyajian dan pengolahan data demografi kesehatan penduduk. Metode pelaksanaan kegiatannya meliputi pelatihan dan pendampingan tentang analisis statistik data demografi kesehatan penduduk yang meliputi pengukuran dasar data demografi kependudukan desa. Hasil dari pelaksanaan kegiatan ini, dapat menunjang pemahaman, menambah pengetahuan dan pengembangan softskill aparat desa dalam mengelola statistik demografi kesehatan penduduk yang berdampak pada peningkatan kualitas pengelolaan dan penataan data kependudukan yang dapat digunakan untuk pembangunan dan mempermudah pelayanan terhadap masyarakat desa.
\end{abstract}

Kata Kunci: Demografi Kesehatan Penduduk, Penyajian dan Pengolahan Data, Softskill Aparat Desa

\begin{abstract}
Negeri Hutumuri is the most populous village in the South Leitimur Subdistrict, Ambon City, with a population of 4,657 people and a population density of 310 people per $\mathrm{km} 2$. The existence of a larger population status profile allows opportunities for various population problems to arise, especially population health, if it is not managed properly. The purpose of this Community Service program is to increase the knowledge of village officials as the spearhead of village development related to the presentation and processing of population health demographic data. The method of implementing its activities includes training and assistance on statistical analysis of population health demographic data which includes basic measurement of village population demographic data. The results of the implementation of this activity can support understanding, increase knowledge and develop soft skills of village officials in managing
\end{abstract}


demographic health statistics of the population which have an impact on improving the quality of management and structuring of population data that can be used for development and facilitating services to village communities.

Keywords: Population Health Demographics, Data Presentation and Processing, Soft Skills for Village Officials.

\section{PENDAHULUAN}

Kota Ambon selain sebagai ibukota dari Provinsi Maluku juga menjadi kota terbesar dengan luas daratan mencapai $359,45 \mathrm{~km}^{2}$ dan perairan sebesar 17,55 $\mathrm{km}^{2}$. Jumlah penduduk Kota Ambon mencapai 384.132 jiwa dengan laju pertumbuhan hasil registrasi periode tahun 2018-2019 sebesar 3,36 persen (https://ambonkota.bps.go.id/, 2020). Secara administratif wilayah Kota Ambon terbagi atas 5 (lima) kecamatan salah satunya adalah Kecamatan Leitimur Selatan. Berdasarkan data Dinas Kependudukan dan Catatan Sipil Kota Ambon Tahun 2019 tercatat jumlah penduduk di Kecamatan Leitimur Selatan sebanyak 10.302 jiwa, dengan komposisi 5.141 penduduk laki-laki dan 5.161 penduduk perempuan dimana Negeri Hutumuri merupakan Negeri terpadat dengan jumlah penduduk mencapai 4.657 jiwa serta kepadatan penduduk sebesar 310 jiwa setiap $\mathrm{km}^{2}$. Dengan status jumlah penduduk yang lebih besar daripada daerah lain secara keseluruhan, maka semakin tinggi pula peluang munculnya berbagai persoalan kependudukan di Negeri Hutumuri khususnya di bidang Kesehatan. Masyarakat diharapkan mampu berperan sebagai pelaku pembangunan kesehatan dalam menjaga, memelihara, dan meningkatkan derajat kesehatannya sendiri serta berperan aktif dalam mewujudkan kesehatan masyarakat (Shalahuddin \& Nurhakim, 2019).

Trend Kependudukan di suatu wilayah/daerah ditentukan oleh trend fertilitas, mortalitas, dan migrasi yang mempengaruhi kuantitas, kualitas penduduk, reit (laju) pertumbuhan penduduk, dan struktur penduduk (Pancasasti dan Khaerunnisa, 2018). Menurut Riyani dkk (2018) mengatakan bahwa permasalahan utama Negara Indonesia sebagai salah satu negara berkembang adalah ledakan jumlah penduduk. Persoalan penduduk memberi dampak yang sangat kompleks dan berdimensi multiple, bahkan melewati batas negara (Suartha, 2016). Oleh sebab itu, sangatlah diperlukan pencatatan jumlah penduduk secara berkala agar supaya dapat diketahui secara jelas perubahan penduduk yang terjadi, baik dalam hal jumlah, komposisi penduduk, laju pertumbuhan atau penurunan penduduk, persebaran dan juga struktur penduduk. Salah satu upaya pencatatan jumlah penduduk yaitu melalui data registrasi penduduk. Registrasi penduduk merupakan pencatatan yang dilakukan terus menerus mengenai kejadian vital yang dialami penduduk (Hanii, 2011).

Registrasi penduduk diantaranya dilakukan dengan pelaporan dari masyarakat kepada instansi pelaksana setempat di Kabupaten/Kota dimana ujung tombak pelaksanaanya adalah Kepala Desa/Kelurahan dengan Perangkat Desa/ Kelurahan yang lain (Jamaluddin, 2020). Seperti yang tertulis dalam Undang-Undang Administrasi Kependudukan "Setiap Penduduk Wajib melaporkan Peristiwa Kependudukan dan Peristiwa Penting yang dialaminya kepada instansi pelaksana dengan memenuhi persyaratan yang diperlukan dalam pendaftaran penduduk dan Pencatatan Sipil". Kenyataan bahwa laju pertumbuhan penduduk yang senantiasa berfluktuasi, maka diperlukan pengetahuan dan pemahaman yang sangat baik oleh staf perangkat desa dalam memanfaatkan data registrasi 
penduduk untuk menghitung ukuran statistik kesehatan penduduk (demografi kependudukan).

Berdasarkan masalah tersebut, maka salah satu solusi yang tepat guna peningkatan kualitas pengelolaan data kependudukan sebagai dasar pengambilan kebijakan oleh Pemerintah Daerah demi peningkatan taraf kesejahteraan dan kesehatan penduduk yakni diperlukannya pelatihan softskills Aparat Desa Negeri Hutumuri dalam pengolahan statistik kependudukan khususnya yang terkait ukuran statistika kesehatan penduduk.

\section{MASALAH}

Permasalahan utama dalam pengabdian ini adalah kurangnya pengetahuan dan pemahaman Aparat Desa Negeri Hutumuri terhadap pentingnya ukuran-ukuran statistik kesehatan dalam demografi kependudukan dengan memanfaatkan data registrasi penduduk yang ada. Diharapkan setelah kegiatan pengabdian ini dapat meningkatkan pengetahuan dan pemahaman Aparat Desa Negeri Hutumuri akan pentingnya pengolahan data statistika kependudukan khususnya yang berkaitan dengan kesehatan penduduk untuk memudahkan Pemerintah Daerah dalam pengambilan kebijakan berdasarkan penyajian data demografi kesehatan penduduk secara lengkap dari tahun ke tahun.

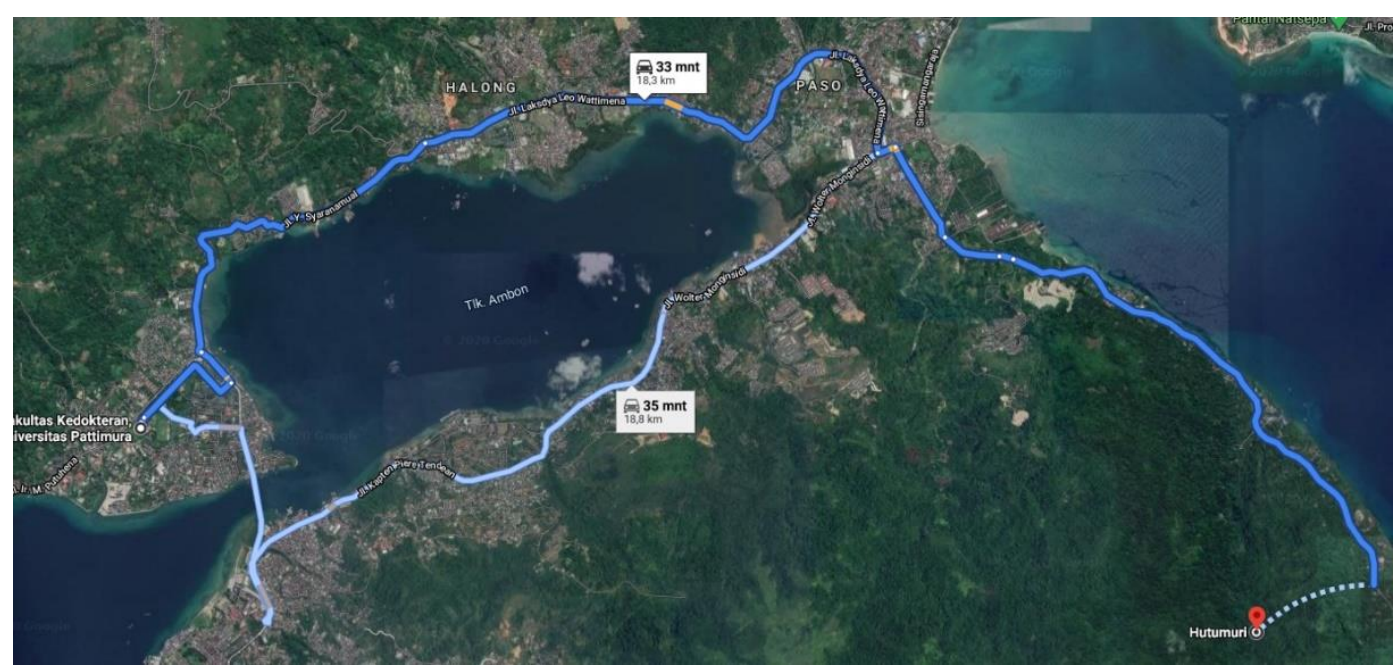

Gambar 2.1. Jarak Kampus Dengan Lokasi Mitra PkM

\section{METODE}

Rangkaian kegiatan inti dalam kegiatan PkM yang dilakukan ini antara lain :

a. Observasi Awal

Observasi dalam kegiatan ini dilakukan guna menganalisis situasi permasalahan yang dihadapi oleh mitra PkM. Dari hasil observasi yang dilakukan melalui diskusi dengan seluruh unsur pejabat negeri Hutumuri ditemui permasalahan yang dihadapi Aparat Desa adalah masih kurangnya pengetahuan dalam penyajian dan pengolahan data demografi kesehatan penduduk mengakibatkan kelengkapan data demografi penduduk tidak tersedia..

b. Pengenalan pengukuran dasar data demografi kesehatan penduduk

Pengenalan pengukuran dasar data demografi kesehatan penduduk kepada Aparat Desa Negeri Hutumuri dimaksudkan untuk membantu dalam penyusunan data statistik kependudukan. Selain itu manfaat dari pengenalan ini adalah untuk meningkatkan pemahaman Aparat Desa Negeri Hutumuri tentang arti pentingnya 
statistik kependudukan di suatu desa sehingga mempermudah pemerintah dalam penyusunan program pembangunan yang menyentuh masyarakat langsung.

C. Pendampingan Penyajian dan Pengolahan data demografi kesehatan penduduk

Pendampingan penyajian dan pengolahan data demografi kesehatan penduduk dilakukan dengan cara memberikan materi pelatihan kepada seluruh Aparat Desa Negeri Hutumuri yang dihadiri sejumlah 10 (sepuluh) orang perangkat desa untuk meningkatkan softskill dalam melakukan analisis statistik kependudukan khususnya ukuran-ukuran dasar terkait kesehatan penduduk. Dalam pemberian materi ini menggunakan media powerpoint dan saat pemberian materi dilakukan dengan metode ceramah dan tanya jawab. Hal ini dimaksudkan sebagai motivasi bagi seluruh Aparat Desa Negeri Hutumuri untuk mengembangkan kemampuan dan pengetahuannya tentang data dan manfaatnya untuk pembangunan di wilayahnya. Setelah proses ceramah dan tanya jawab berakhir, kegiatan dilanjutkan dengan praktek pengukuran data statistik kependudukan yang didampingi salah satu dosen tim dan satunya lagi bertindak sebagai moderator dan penyaji. Saat praktik tersebut tentunya dibutuhkan datadata kependudukan, maka dari itu disediakan data kependudukan sebagai contoh yang bersumber dari BPS Kota Ambon. Pada tahap ini data diolah kemudian di analisis sehingga peserta dapat menerapkan sesuai ketersediaan data.

d. Evaluasi pelaksanaan dan Keberlanjutan Program Di Lapangan

Langkah evaluasi pelaksanaan program Pendampingan penyajian dan pengolahan data demografi kesehatan penduduk kepada Aparat Desa Negeri Hutumuri yaitu peserta diarahkan untuk melakukan praktek secara mandiri. Dalam tahap ini tim pengabdian semuanya sebagai pemantau, jika ada peserta yang bertanya maka tim pengabdian diperkenankan untuk menjawab dan membantu dalam analisis data. Dengan langkah ini evaluasi pemahaman peserta tentang materi pelatihan dapat diukur. Keberlanjutan dari kegiatan pengabdian ini setelah selesai dilaksanakan adalah pengetahuan Perangkat Desa Aparat Desa Negeri Hutumuri jadi meningkat dan diharapkan terampil dalam mengolah dan menganalisis data kependudukan. Selanjutnya diharapkan dapat terbentuk petugas khusus negeri yang bertugas menghitung dan menganalisis pengukuran demografi kesehatan penduduk. Petugas khusus negeri yang bertugas sampai dengan penjadwalan kegiatan pengabdian ini berakhir tetap berkoordinasi dan didampingi oleh tim pengabdian.

\section{HASIL DAN PEMBAHASAN}

Program inti pelaksanaan tim PkM Fakultas Kedokteran Universitas Pattimura Tahun 2020 periode November-Desember dengan tema "Pendampingan Penyajian dan Pengolahan Data Demografi Kesehatan Penduduk Aparat Desa Negeri Hutumuri Kecamatan Leitimur Selatan Kota Ambon" Kegiatan pengabdian ini terselenggara atas kerjasama dengan Pemerintah Negeri Hutumuri Kecamatan Leitimur Selatan. Kegiatan pelatihan kepada Aparat Desa ini merupakan salah satu tahapan penting dari kegiatan pengabdian kepada masyarakat sebagai bagian Tridharma Perguruan Tinggi yang diawali dengan menganalisis situasi permasalahan yang dihadapi oleh mitra PkM. Dari hasil observasi yang dilakukan melalui diskusi dengan seluruh unsur pejabat negeri Hutumuri ditemui permasalahan yang dihadapi Aparat Desa adalah masih kurangnya pengetahuan dalam penyajian dan pengolahan data demografi kesehatan penduduk mengakibatkan kelengkapan data demografi penduduk tidak tersedia. 
Pelaksanaan kegiatan sosialisasi pengenalan pengukuran dasar data demografi kesehatan penduduk kepada Aparat Desa Negeri Hutumuri dilaksanakan pada tanggal 30 November 2020 mulai jam 14.00 WIT hingga selesai. Kegiatan sosialisasi bertempat di Aula kantor Negeri Hutumuri Kecamatan Leitimur Selatan Kota Ambon. Yang memberi kata sambutan dalam sosialisasi ini adalah Raja Negeri Hutumuri sehingga kegiatan berlangsung lancar dengan suasana kenyamanan. Sedangkan sebagai narasumber kegiatan ini terdiri dari dua orang dosen yakni yang pertama dr.Johan B. Bension, M.MedEd yang bertindak selaku Ketua tim PkM dengan materi yang dibawakan adalah pengenalan ukuranukuran dasar demografi kesehatan kemudian yang kedua oleh F. Kondo Lembang, S.Si.,M.Si sebagai anggota tim PkM memberikan simulasi perhitungan ukuranukuran dasar demografi kesehatan penduduk yang turut dibantu beberapa mahasiswa.

Dalam pelaksanaan kegiatan ini turut dihadiri oleh antara lain Bapak Raja Negeri beserta seluruh staf. Peserta yang hadir tampak sangat antusias mendengarkan ceramah yang disampaikan, hal ini tampak dari beberapa orang peserta bertanya dan ingin mendapatkan penjelasan lebih mendalam tentang permasalahan yang menyangkut konsep perhitungan ukuran-ukuran dasar demografi kesehatan penduduk. Setelah tahapan sosialisasi dan pendampingan penyajian dan pengolahan ukuran-ukuran dasar demografi kesehatan penduduk selesai dilakukan maka tahapan berikutnya adalah evaluasi pelaksanaan program Pendampingan penyajian dan pengolahan data demografi kesehatan penduduk kepada Aparat Desa Negeri Hutumuri yaitu peserta diarahkan untuk melakukan praktek secara mandiri. Dalam tahap ini tim pengabdian semuanya sebagai pemantau, jika ada peserta yang bertanya maka tim pengabdian diperkenankan untuk menjawab dan membantu dalam analisis data. Dengan langkah ini evaluasi pemahaman peserta tentang materi pelatihan dapat diukur.

Keberlanjutan dari kegiatan pengabdian ini setelah selesai dilaksanakan adalah pengetahuan Perangkat Desa Aparat Desa Negeri Hutumuri jadi meningkat dan diharapkan terampil dalam mengolah dan menganalisis data demografi kesehatan penduduk. Selanjutnya diharapkan dapat terbentuk petugas khusus negeri yang bertugas menghitung dan menganalisis pengukuran demografi kesehatan penduduk. Petugas khusus negeri yang bertugas sampai dengan penjadwalan kegiatan pengabdian ini berakhir tetap berkoordinasi dan didampingi oleh tim pengabdian. Berikut ini dapat disajikan beberapa hasil pengukuran ukuran-ukuran dasar demografi kesehatan penduduk sesuai dengan ketersediaan data real yang bersumber dari profil Negeri Hutumuri Tahun 2020 :

* Angka Kelahiran Kasar (Crude Birth Rate) Negeri Hutumuri mencapai 4 kelahiran per seribu penduduk.

* Angka Kematian Kasar (Crude Death Rate) Negeri Hutumuri mencapai 9 orang per seribu penduduk.

* Hasil Perhitungan Sex Ratio (SR) Negeri Hutumuri sebesar 97 yang artinya terdapat 97 penduduk laki-laki diantara 100 penduduk wanita.

Pertumbuhan penduduk yang tinggi dengan angka fertilitas dan angka mortalitas yang relatif tinggi, dimana kondisi ini dianggap tidak menguntungkan dari sisi pembangunan ekonomi, pembangunan manusia (sosial). Selain menimbulkan berbagai macam masalah sosial, jumlah penduduk yang semakin bertambah juga menimbulkan dampak pada masalah yang lain, yaitu masalah lingkungan. Semakin banyak penduduk berarti semakin banyak areal persawahan dan hutan yang berubah fungsi menjadi pemukiman penduduk. Berbagai persoalan akan muncul akibat masalah kependudukan, walaupun pada dasarnya 
jika jumlah penduduk yang banyak selaras dengan kualitas manusia (sumber daya manusia) akan membantu meringankan permasalahan tersebut.

Penduduk merupakan salah satu faktor penting dalam perencanaan pembangunan daerah. Karena penduduk merupakan sumber daya manusia yang partisipasinya sangat diperlukan agar perencanaan dapat berjalan dengan baik. Penduduk juga merupakan motor penggerak pembangunan sehingga tidak dapat dilepaskan peranannya dalam pembangunan daerah. Selain sebagai subjek dalam proses pembangunan, penduduk dapat juga bertindak sebagai objek, dimana ia akan menjadi target dalam setiap proses pembangunan. Oleh karena itu analisis kependudukan sangat efesiensi dan efektivitas perencanaan pembangunan agar berhasil sebagaimana diharapkan.

Dalam analisis kependudukan, banyak faktor yang perlu diperhatikan dan dianalisis sehingga dapat memberikan informasi akurat dalam rangka menentukan berbagai keputusan yang akan diambil selama proses perumusan Perencanaan Pembangunan Daerah. Penduduk pada dasarnya merupakan target utama yang ingin dituju oleh setiap proses pembangunan, yaitu berupa peningkatan kesejahteraan masyarakat. Hal yang bisa dianalisis dalam hal kependudukan pada umumnya menyangkut masalah yang berkaitan dengan perubahan keadaan penduduk seperti kelahiran, kematian, jumlah penduduk berdasarkan jenis kelamin, proyeksi jumlah penduduk dan perkembangan penduduk. Faktor - faktor tersebut memiliki peranan penting sebagai bahan yang perlu diketahui dalam rangka menentukan berbagai keputusan yang berkaitan dengan proses pembangunan.

Dari Hasil Pelatihan yang diawali dengan sosialisasi data demografi kesehatan penduduk bagi aparat negeri Hutumuri, bahwa ada beberapa data yang perlu dilakukan pengukuran data sehingga dapat dimanfaatkan untuk pembangunan. Dengan demikian pengetahuan yang telah diperoleh dapat membantu pemerintah dalam perencanaan pembangunan dibidang kesehatan penduduk untuk kesejahteraan masyarakatnya. Selain itu diharapkan aparat negeri Hutumuri dapat memberikan edukasi dan pendampingan kepada masyarakat agar penduduknya tertib dalam administrasi kependudukan. Hambatan yang ditemui pada saat penyuluhan adalah menyesuaikan jadwal aparat desa dengan jadwal kegiatan pemateri. Selain itu jauhnya keberadaaan Negeri Hutumuri diukur dari jarak dengan mitra juga menjadi kendala untuk berkunjung ke wilayah ini dan melakukan edukasi bagi aparat negeri dan masyarakat. Seluruh peserta penerima materi berharap akan ada keberlanjutan kegiatan ini dengan penyuluhan penyuluhan materi lainnya serta adanya pembinaan dan pendampingan. Berikut ditampilkan dokumentasi kegiatan yang dilakukan : 


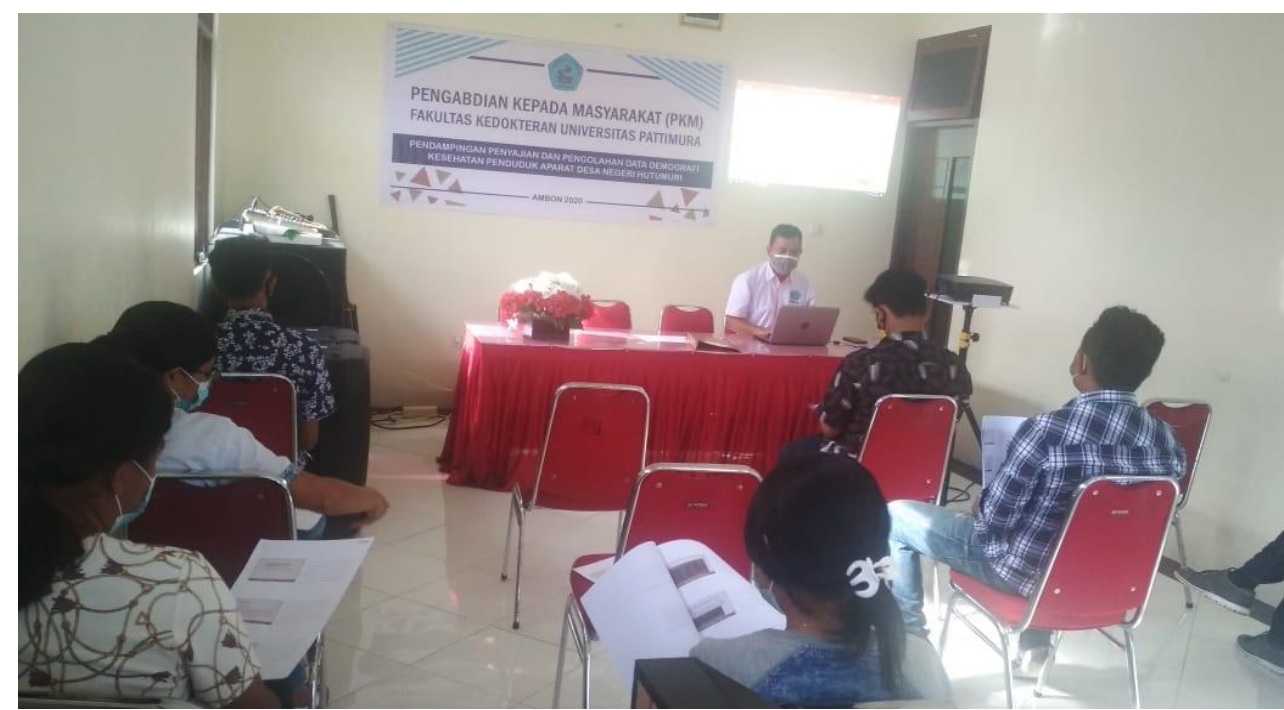

Gambar 4.2. Dokumentasi Kegiatan PkM

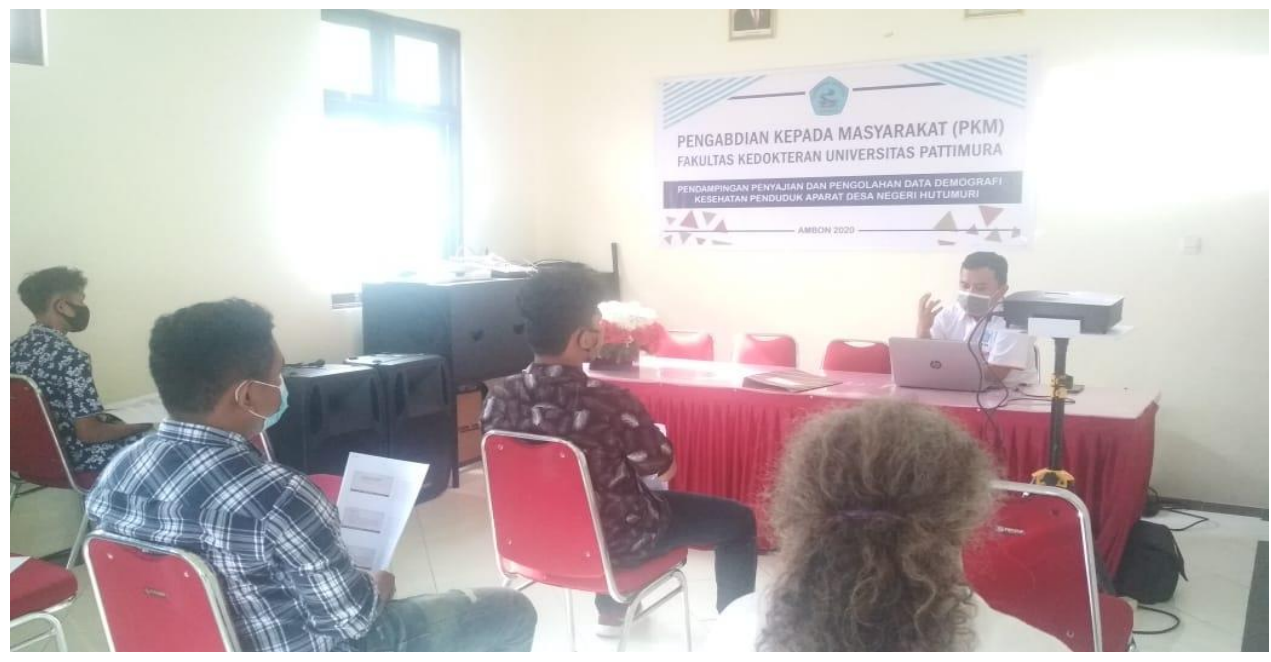

Gambar 4.2. Dokumentasi Kegiatan PkM

\section{KESIMPULAN}

Pelaksanaan kegiatan pengabdian masyarakat oleh Tim dosen Fakultas Kedokteran dan Fakultas MIPA Tahun 2020 yaitu pendampingan penyajian dan pengolahan data demografi kesehatan penduduk aparat desa negeri Hutumuri Kecamatan Leitimur Selatan Kota Ambon. Sosialisasi pendampingan penyajian dan pengolahan data demografi kesehatan penduduk bagi aparat desa negeri Hutumuri memudahkan pemangku kepentingan dalam hal ini pemerintah negeri untuk pengambilan kebijakan pembangunan desa secara tepat melalui kelengkapan data yang telah tersedia. Kegiatan pendampingan penyajian dan pengolahan data demografi kesehatan penduduk bagi aparat desa negeri Hutumuri dapat memotivasi pengembangan pengetahuan tentang demografi sehingga kegiatan ini perlu dilakukan secara berkelanjutan. 


\section{DAFTAR PUSTAKA}

BPS, (2020). Kota Ambon Dalam Angka 2020. Badan Pusat Statistik Kota Ambon. Hanii, (2011). Pengertian-Pengertian Tentang Sensus, Registrasi, Survey Penduduk. (http :// www.hanifahhani12.blogspot.co.id).

Jamaluddin, T. (2020). Registrasi Penduduk Sebagai Syarat Lahirnya Hak dan Kewajiban (Studi Perbandingan Hukum Islam dan Undang-Undang Nomor 24 Tahun 2013 Tentang Administrasi Kependudukan). Skripsi, Fakultas Syariah dan Hukum, Program Studi Perbandingan Mazhab dan Hukum, Universitas Islam Negeri Ar-Raniry. Banda Aceh.

Nilakusumawati, D. (2009). Matematika Populasi. Udayana University Press.

Pancasasti, R \& Khaerunnisa, E., (2018). Analisis Dampak Laju Pertumbuhan Penduduk Terhadap Aspek Kependudukan Berwawasan Gender Pada Urban Area di Kota Serang. Jurnal EKONOMIKA. 13(1). 130-145.

Republik Indonesia, Undang-Undang Nomor 24 Tahun 2013, Lembar Negara Tahun 2013 No.24.

Rilyani, Furqoni. P.D., Triyoso, Korip, P. (2018). Penyuluhan Kontrasepsi Guna Meningkatkan Pengetahuan Kesehatan Reproduksi Pasangan Usia Subur Di Puskesmas Way Panji Lampung Selatan Tahun 2017. Jurnal Kreativitas Pengabdian Kepada Masyarakat (PkM). 1(1). 31-35

Shalahuddin. I., \& Nurhakim. F. (2019). Pendidikan/Penyuluhan Kesehatan Tentang PHBS Tatanan Rumah Tangga di RW 09 Desa Jayaraga Garut, Jawa Barat. Jurnal Kreativitas Pengabdian Kepada Masyarakat (PkM). 2(1). 73 82.

Suartha, N. (2016). Faktor-Faktor yang Mempengaruhi Tingginya Laju Pertumbuhan dan Implementasi Kebijakan Penduduk di Provinsi Bali. Jurnal PIRAMIDA. 12(1). 1-7.

WHO (2015). World Health Statistics : World Health Organization. 